\title{
Neutrophil recruitment in endotoxin-induced murine mastitis is strictly dependent on mammary alveolar macrophages
}

\author{
Sharon ElAZAR ${ }^{1}$, Erez Gonen ${ }^{1}$, Ayala Livneh-Kol ${ }^{1}$, Ilan Rosenshine ${ }^{2}$, \\ Nahum Yehuda SHPIGEL ${ }^{1 *}$ \\ ${ }^{1}$ The Koret School of Veterinary Medicine, Faculty of Agriculture, The Hebrew University of Jerusalem, \\ POB 12, Rehovot 76100, Israel \\ 2 Department of Microbiology and Molecular Genetics, IMRIC, Faculty of Medicine, \\ The Hebrew University of Jerusalem, POB 12272, Jerusalem 91120, Israel
}

(Received 14 July 2009; accepted 7 October 2009)

\begin{abstract}
Mastitis, inflammation of the mammary tissue, is a common disease in dairy animals and mammary pathogenic Escherichia coli (MPEC) is a leading cause of the disease. Lipopolysaccharide (LPS) is an important virulence factor of MPEC and inoculation of the mammary glands with bacterial LPS is sufficient to induce an inflammatory response. We previously showed using adoptive transfer of normal macrophages into the mammary gland of TLR4-deficient $\mathrm{C} 3 \mathrm{H} / \mathrm{HeJ}$ mice that LPS/TLR4 signaling on mammary alveolar macrophages is sufficient to elicit neutrophil recruitment into the alveolar space. Here we show that TLR4-normal $\mathrm{C} 3 \mathrm{H} / \mathrm{HeN}$ mice, depleted of alveolar macrophages, were completely refractory to LPS intramammary challenge. These results indicate that alveolar macrophages are both sufficient and essential for neutrophil recruitment elicited by LPS/TLR4 signaling in the mammary gland. Using TNF $\alpha$ gene-knockout mice and adoptive transfer of wild-type macrophages, we show here that TNF $\alpha$ produced by mammary alveolar macrophages in response to LPS/TLR4 signaling is an essential mediator eliciting blood neutrophil recruitment into the milk spaces. Furthermore, using the IL8 receptor or IL1 receptor geneknockout mice we observed abrogated recruitment of neutrophils into the mammary gland and their entrapment on the basal side of the alveolar epithelium in response to intramammary LPS challenge. Adoptive transfer of wild-type neutrophils to IL1 receptor knockout mice, just before LPS challenge, restored normal neutrophil recruitment into the milk spaces. We conclude that neutrophil recruitment to the milk spaces is: (i) mediated through TNF $\alpha$, which is produced by alveolar macrophages in response to LPS/ TLR4 signaling and (ii) is dependent on IL8 and IL1 $\beta$ signaling and regulated by iNOS-derived NO.
\end{abstract}

\section{mastitis / lipopolysaccharide / macrophage / neutrophil / murine model}

\section{INTRODUCTION}

Mastitis, inflammation of the mammary tissue, is a common disease in dairy animals and a worldwide problem, leading to multibillion dollar economic losses [3, 11]. Mastitis is caused

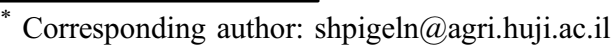

by bacterial invasion and colonization of the teat canal and mammary pathogenic Escherichia coli (MPEC) is a leading cause of the disease in dairy animals $[22,32]$. Although specific virulence factors have not been identified, the microbial cell wall component, lipopolysaccharide (LPS), is an important virulence factor of MPEC. Inoculation of the mammary gland with bacterial LPS is sufficient to induce an 
inflammatory response [2] initiated by LPS/ TLR4 signaling [10]. The innate response to pathogen invasion of the mammary gland is likely to be dictated by tissue-resident macrophages, as well as epithelial cells, that are exposed to the alveolar and duct spaces. Prime candidates for the first line of defense against invading bacteria and their products are alveolar macrophages that are present in normal mammary secretion and milk [27]. Both alveolar macrophages and epithelial cells were shown in vitro to respond to microbes by eliciting inflammatory mediators and modulators $[18,27]$ that strongly attract neutrophils to migrate across the polarized alveolar epithelial layer into the lumen $[24,25]$. However, our study using adoptive transfer of normal macrophages into the mammary gland of TLR4-deficient $\mathrm{C} 3 \mathrm{H} / \mathrm{HeJ}$ mice, challenged with LPS, showed that alveolar macrophages are sufficient to elicit neutrophil recruitment into the alveolar space [10]. Furthermore, we found the highest levels of TLR4 and CD14 expression on mammary macrophages and that mammary dendritic cells (DC) were ignorant to the LPS challenge [10].

The aim of the present work was to determine if neutrophil recruitment in response to LPS is strictly dependent on mammary alveolar macrophages and to elucidate the signals involved in this neutrophil recruitment.

\section{MATERIALS AND METHODS}

\subsection{Intramammary mouse LPS challenge}

Six to eight week-old female $\mathrm{C} 3 \mathrm{H} / \mathrm{HeN}, \mathrm{BALB} / \mathrm{c}$, C57BL/6, TNF $\alpha$ gene-deficient (TNF $\alpha-/-)$, CXC chemokine receptor-2 gene-deficient (CXCR2 -/-), iNOS gene-deficient (iNOS $-/-$ ) and IL-1 receptor type 1 gene-deficient (IL-1R -/-) mice were used in this study. All knockout mice were purchased from The Jackson Laboratory (Bar Harbor, Main, USA) and are described in the $\mathrm{JAX}^{\circledR}$ Mice Database ${ }^{1}$. Mice were maintained under specific pathogen free conditions and handled under protocols approved by the Hebrew University Animal Care and Use Committee, according to international guidelines. LPS

\footnotetext{
${ }^{1}$ http://www.jax.org/
}

intramammary challenge was performed 7-10 days post partum. LPS was purchased as lyophilized, purified E. coli 0111:B4 (L3024, Sigma, St. Louis, MO, USA). This LPS preparation was tested in vitro and it does not contain other TLR ligands in detectable levels (data not shown). Mice were challenged via teat canal catheterization with $10 \mu \mathrm{L}$ of LPS solution $(10 \mu \mathrm{g})$ as previously described [10]. The challenged gland was the abdominal L4, whereas abdominal R4 was injected with PBS only as a control in the same manner.

\subsection{Mammary alveolar macrophage depletion}

Mammary alveolar macrophages were depleted by intramammary infusion of $50 \mu \mathrm{L}$ of clodronate liposomes (containing dichloromethylene diphosphonate, $\mathrm{CL}_{2} \mathrm{MDP}$, a gift from Boehringer Mannheim $\mathrm{GmbH}$, Mannheim, Germany). Contralateral control glands were similarly infused with saline liposomes. All liposomes were prepared and supplied by $\mathrm{N}$. van Rooijen as previously described [37]. Liposomes were infused into the teat canal of lactating mice $24 \mathrm{~h}$ before LPS challenge using the above-described technique.

\subsection{Adoptive transfer of macrophages}

Wild-type C57BL/6 mouse peritoneal macrophages were harvested by peritoneal lavage with $10-\mathrm{mL}$ cold PBS 3 days following intraperitoneal injection of $1 \mathrm{~mL}$ sterile $3 \%$ thioglycollate medium (Hylabs, Rehovot, Israel). Peritoneal cells were centrifuged at $400 \times g$ for $10 \mathrm{~min}$ at $4{ }^{\circ} \mathrm{C}$ and washed with PBS. Cells were resuspended in complete media; DMEM medium was supplemented with $4 \mathrm{mM}$ L-glutamine, $1 \%$ penicillin/streptomycin, $10 \%$ heat-inactivated fetal bovine serum (Biological Industries, Kibbutz Beit Haemek, Israel), and $25 \mathrm{mM}$ HEPES (Gibco), and incubated at $37^{\circ} \mathrm{C}$ and $5 \% \mathrm{CO}_{2}$ in $75 \mathrm{~mm}^{2}$ tissue culture flasks. Nonadherent cells were removed by washing with ice-cold PBS and adherent cells were allowed to incubate for 5 days. Cells were harvested by incubating with $0.05 \%$ trypsin/EDTA (1:5 000) solution (Biological Industries) after which macrophages were resuspended in complete media without penicillin/streptomycin, enumerated with a hemocytometer and viability was assessed by trypan blue exclusion. Cells were collected by centrifugation, resuspended in PBS in the required concentration of $2 \times 10^{5}$ cells in $50 \mu \mathrm{L}$. Based on Diff-Quik-stained cytospin preparation and flow cytometry analysis using F4/80 monoclonal antibodies, the cell suspension contained 
$>98 \%$ macrophages. Macrophages were infused into the teat canal of lactating mice just before LPS challenge using the above-described technique.

\subsection{Adoptive transfer of neutrophils}

Wild-type C57BL/6 mice were euthanized and bone marrow from the tibias and femurs was flushed with PBS. Harvested bone marrow was passed through a nylon cell strainer, washed twice in $10 \mathrm{~mL}$ PBS and placed on $10 \mathrm{~mL}$ Histopaque 1080 (Sigma, Rehovot, Israel) followed by centrifugation at $1000 \mathrm{~g}$ for $30 \mathrm{~min}$. The neutrophil pellet was then isolated, and red blood cells were lysed for $1 \mathrm{~min}$ with double volumes of distilled water, followed by a fast recovery of isotonicity with $10 \times$ PBS. Cells were then washed twice by centrifugation in PBS, resuspended and enumerated with a hemocytometer and viability was assessed by trypan blue exclusion. The cell suspension, based on a Diff-Quik-stained cytospin preparation, contained $>90 \%$ neutrophils. Adoptive transfer of wt neutrophils was performed by injecting $10^{6}$ neutrophils in $100 \mu \mathrm{L}$ into the coccygeal vein of IL-1R -/ - mice immediately before intramammary LPS challenge.

\subsection{Histochemical analysis}

Gland tissues were trisected for cytokines, chemokines and myeloperoxidase (MPO) assays, histology and immunohistochemistry. Samples for histological analysis were fixed in neutral buffer $4 \%$ formaldehyde, paraffin-embedded, and sections were cut and stained with haematoxylin and eosin (HE). Fresh mammary tissue for fluorescence staining was fixed in $2.5 \%$ paraformaldehyde over-night at room temperature, incubated with $15 \%$ sucrose for $12 \mathrm{~h}$ at $4{ }^{\circ} \mathrm{C}$ and frozen in Tissue-Tek ${ }^{\circledR}$ (EMS, Hatfield, PA, USA) embedding medium. Serial cryosections of $5 \mu \mathrm{m}$ were stained with CMTMR (CellTracker ${ }^{\mathrm{TM}}, 0.1 \mu \mathrm{M}$, Invitrogen, Carlsbad, CA, USA) or phalloidin-rhodamine (Sigma). Sections for immunohistochemistry were blocked with $3 \mu \mathrm{g} / \mathrm{mL}$ $\mathrm{IgG}$ (Caltag, Invitrogen) for $1 \mathrm{~h}$ at room temperature. For CD68 staining, permeabilization (with $0.1 \%$ saponin and $1 \%$ BSA) was performed prior to using CD68 mAb (eBioscience) and anti-rat IgG Alexafluor $594 \mathrm{Ab}$ (Invitrogen). Samples were mounted with VectaShield ${ }^{\circledR}$ containing $4^{\prime}, 6^{\prime}$-diamidino2-phenylindole (DAPI) (Vector Laboratories, Burlingame, CA, USA) and imaged with a Zeiss Axioscope II fluorescent microscope for 3 color imaging. Image acquisition was conducted with Simple PCI software.

\subsection{Cytokines, chemokines and MPO assays}

For the cytokines, chemokines and MPO assays, $100 \mathrm{mg}$ of mammary gland tissue was homogenized on ice in $1 \mathrm{~mL}$ of sterile $0.025 \%$ Triton X-100/PBS. After homogenization, samples were centrifuged $(10000 \mathrm{~g})$ for $5 \mathrm{~min}$ at $4{ }^{\circ} \mathrm{C}$ and then the supernatant was removed, aliquoted and frozen at $-80{ }^{\circ} \mathrm{C}$. Total protein concentration was determined by the Bradford assay (Sigma) and the concentrations of interleukin $1 \beta$ (IL1 $\beta$ ), tumor necrosis factor $\alpha$ $(\mathrm{TNF} \alpha)$, keratinocyte derived chemokine $(\mathrm{KC})$ and macrophage inflammatory protein-2 (MIP-2) were measured in duplicate by mouse ELISA (R\&D Systems, Minneapolis, MN, USA), according to the manufacturers' instructions. Cytokine and chemokine levels were reported per mg total protein.

MPO activity in mammary tissue homogenates was measured as previously reported [10]. Briefly, colorimetric reaction in triplicate samples was used to compare MPO activity in the inoculated glands and the contralateral control gland using tetramethyl benzidine (TMB, Vector Labs.) as the substrate at a wavelength of $450 \mathrm{~nm}$. A standard curve relating known MPO activity (MPO, Sigma) with the absorbance was obtained and total MPO activity was calculated as $\mathrm{mU}$ per $\mathrm{mg}$ total protein. The relative MPO activity was calculated by the ratio between total MPO activity measured in the LPS-challenged gland and in the contralateral, unchallenged controlled gland.

\subsection{Statistical analysis}

Relative MPO activity and concentrations of IL1 $\beta$, TNF $\alpha, \mathrm{KC}$ and MIP-2 are reported as the means \pm standard errors of the means (S.E.) of values obtained from at least two different experiments and $n \geq 6$ /group. Comparisons of the means were tested with the $t$-test for paired values. A $p$ value of 0.05 or less was considered significant.

\section{RESULTS}

\subsection{Mammary alveolar macrophages are essential for LPS/TLR4 signaling}

To investigate the role of mammary alveolar macrophages in LPS-induced murine mastitis, we examined the effect of depleting this population using liposome-encapsulated clodronate. Clodronate liposomes or saline liposomes were infused into the teat canal 1 day before 

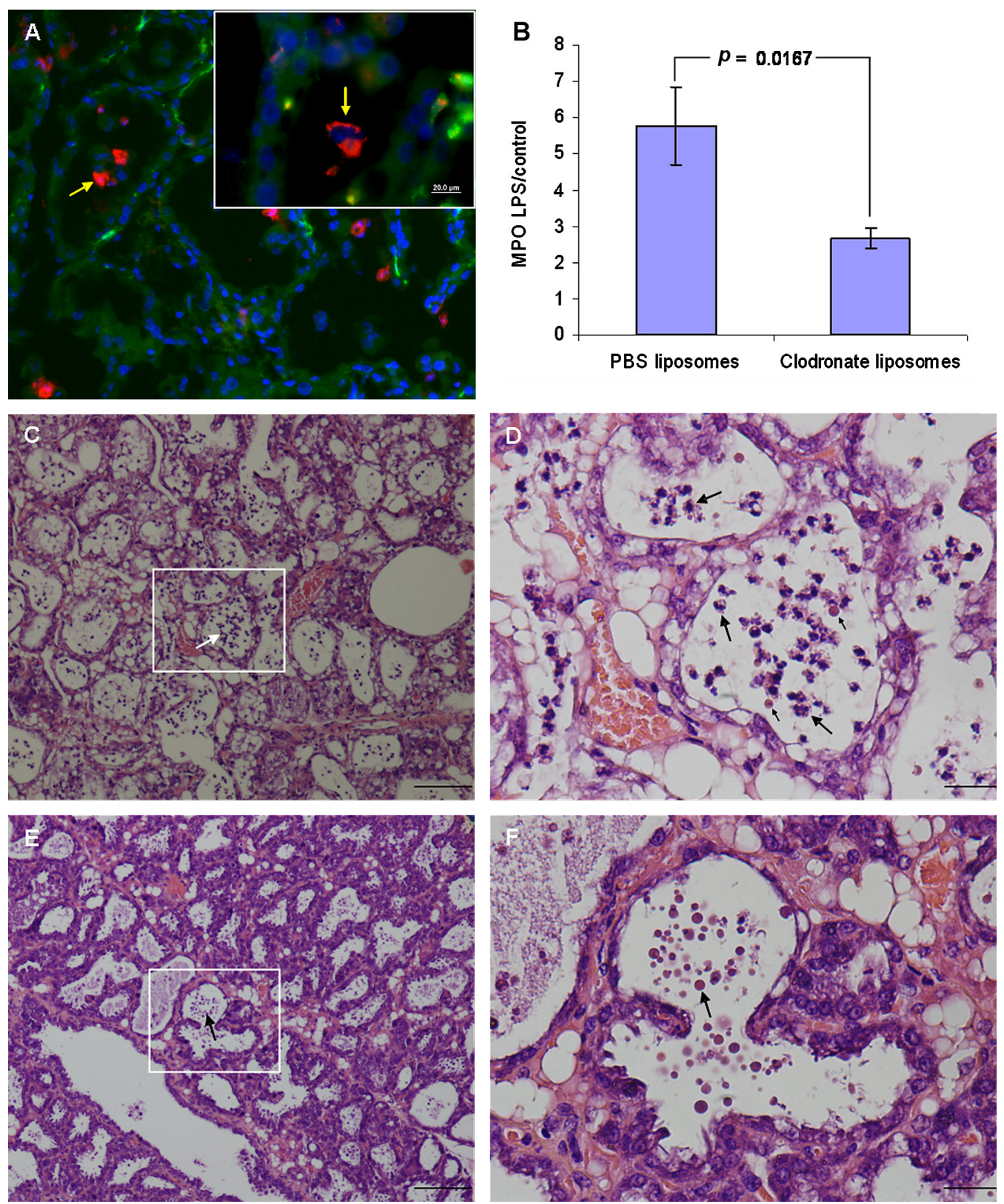

Figure 1. Mammary alveolar macrophages are essential for neutrophil recruitment elicited by LPS/TLR4 signaling in the mammary gland. Alveolar macrophages are demonstrated in the normal mammary gland of C57BL/6 mouse by fluorescence staining with DAPI, CMTMR and anti CD68 mAb (red on line) of cryosection (arrows in A). Mammary glands of lactating $\mathrm{C} 3 \mathrm{H} / \mathrm{HeN}$ mice were infused with either liposomeencapsulated PBS (C and D) or clodronate (E and F) followed by intramammary infusion of $10 \mu \mathrm{g}$ LPS. $\mathrm{H} \& \mathrm{E}$ staining of formalin-fixed mammary tissues $24 \mathrm{~h}$ after LPS inoculation $(\mathrm{C}-\mathrm{F})$. Inserts of $\mathrm{C}$ and $\mathrm{E}$ are magnified in D and F. LPS infused into the alveolar macrophages-depleted gland failed to induce disease 
intramammary LPS challenge. Histological analysis showed that steady state macrophages are localized in the interstitium and occasionally the alveolar space (Fig. 1A). Intramammary clodronate infusion eliminated alveolar macrophages but the interstitial macrophage population remained unaffected. Liposomes are probably highly stable in milk since they were visualized by fluorescence microscopy for up to 9 days after intramammary infusion (Supplementary material available on line at www.vetres.org Figs. S1A and S1B, $24 \mathrm{~h}$ after infusion). We previously showed that intramammary LPS challenge stimulates interstitial macrophage recruitment into the alveolar spaces [10]. Although interstitial macrophages were unaffected by intramammary clodronate infusion (liposomes were not observed outside the milk spaces), macrophages trafficking into the alveolar space were eliminated by the liposome-clodronate persisting in this space.

Histopathological examination of mammary gland infused with saline liposomes $24 \mathrm{~h}$ before LPS challenge revealed massive recruitment of neutrophils into the alveolar spaces and milk ducts. No signs of inflammation were present in the interstitial tissue, and the blood vessels as well as the ductal and alveolar epithelium maintained normal morphology (Figs. 1C and 1D). Mammary glands infused with clodronate liposomes $24 \mathrm{~h}$ before LPS challenge were not inflamed and were free of disease signs and symptoms (Figs. 1E and 1F). To substantiate these results, we used the MPO assay to quantify the levels of neutrophil infiltration into the mammary glands upon LPS treatment. Whereas the LPS challenge resulted in a marked increase of MPO activity in the saline-liposome pretreated mammary glands, MPO activity in the clodronate-liposome pretreated mammary glands remained low upon LPS treatment $(p=0.0167)$ (Fig. 1B)

\subsection{Production of mammary inflammatory cytokines and chemokines is dependent on LPS/TLR4 signaling in alveolar macrophages}

To investigate the down-stream signals elicited by LPS/TLR4 signaling in alveolar macrophages, we analyzed the concentrations of IL1 $\beta$, $\mathrm{TNF} \alpha, \mathrm{KC}$ and MIP-2 in mammary gland homogenates of $\mathrm{C} 3 \mathrm{H} / \mathrm{HeN}$ and TLR4-deficient, $\mathrm{C} 3 \mathrm{H} / \mathrm{HeJ}$ mice $24 \mathrm{~h}$ after intramammary challenged with LPS. Blood neutrophil recruitment and mammary inflammation in $\mathrm{C} 3 \mathrm{H} / \mathrm{HeN}$ mice following LPS/TLR4 signaling in alveolar macrophages was previously described [10]. This was associated with high concentrations of IL1 $\beta$, TNF $\alpha$, KC and MIP-2 in the mammary tissues (Fig. 2). The refractory state of the TLR4-deficient $\mathrm{C} 3 \mathrm{H} / \mathrm{HeJ}$ mouse to LPS challenge was previously described [11] and is also reflected here by the basal levels of IL1 $\beta, T N F \alpha$, $\mathrm{KC}$ and MIP-2 in the mammary tissue (Fig. 2).

\subsection{TNF $\alpha$ is essential for neutrophil recruitment after LPS/TLR4 signaling on alveolar macrophages}

To investigate the role of TNF $\alpha$ as a downstream signal elicited by LPS/TLR4 signaling, $\mathrm{TNF} \alpha-/-$ mice were intramammarlly challenged with LPS. Mammary glands of TNFa $-/-$ mice infused with $10 \mu \mathrm{g}$ of LPS were not inflamed and remained free of disease signs

(E and F), only liposomes are visible in the alveolar spaces (arrows in E and F) while neutrophil recruitment into the alveolar space is clearly visible (large arrows in C and D) together with the control PBS-liposomes (small arrows in D). Neutrophil recruitment to the mammary gland was assessed by the MPO assay (B). Significant difference in relative (LPS to PBS-challenged gland) MPO activity was observed in the mammary glands of $\mathrm{C} 3 \mathrm{H} / \mathrm{HeN}$ mice infused with PBS-liposomes compared with clodronate-liposome infused mice $24 \mathrm{~h}$ after intramammary challenge with $10 \mu \mathrm{g}$ LPS. Data are mean and S.E., $n \geq 6$ /group and $p$ value compared PBS-liposome with clodronate-liposome infused mice using the Student $t$-test. Scale bars $20 \mu \mathrm{m}$ (A), $200 \mu \mathrm{m}$ (C and E), $50 \mu \mathrm{m}$ (D and F). (A color version of this figure is available at www.vetres.org.) 

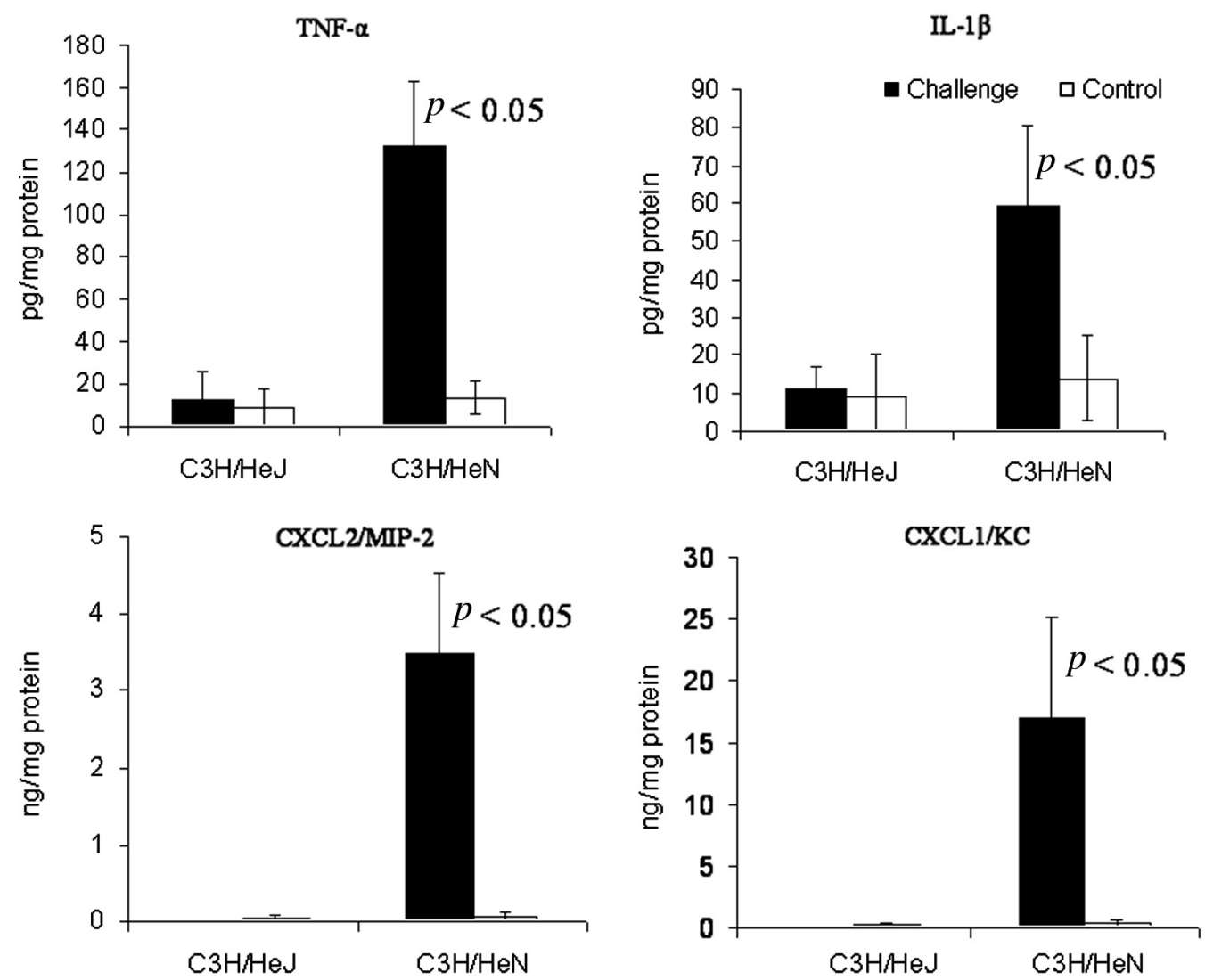

Figure 2. Mammary cytokine and chemokine concentrations $24 \mathrm{~h}$ after intramammary infusion of $10 \mu \mathrm{g}$ LPS in $\mathrm{C} 3 \mathrm{H} / \mathrm{HeN}$ and $\mathrm{C} 3 \mathrm{H} / \mathrm{HeJ}$ mice. Bars represent mean concentrations per mg total protein and S.E. of TNF $\alpha$, IL-1 $\beta$, MIP-2 (CXCL2) and KC (CXCL1) measured by ELISA in tissue homogenates of LPS and PBS-infused control glands of 6 mice in two different experiments. $p<0.05$ value compared means between LPS and PBS-infused control glands using the Student $t$-test.

and symptoms (Fig. 3B). We further used the MPO assay to compare the levels of neutrophil infiltration into the mammary glands upon LPS treatment. Importantly, whereas the LPS challenge resulted in a marked increase of MPO activity in the mammary glands of C57BL/6 mice, MPO activity in the mammary glands of $\mathrm{TNF} \alpha-/-$ mice remained low upon LPS treatment, similar to that found in the salineinfused control gland (Fig. 3D).

To investigate the specific contribution of alveolar macrophages in LPS/TLR4-mediated $\mathrm{TNF} \alpha$ production, we used the procedure of intramammary adoptive transfer of wt C57BL/6 macrophages to TNF $\alpha-/-$ mice. To this end, wt peritoneal macrophages were harvested and introduced into the mammary glands of TNFa $-/-$ recipients mice just prior to LPS infusion. Whereas LPS inoculated into the mammary glands of TNF $\alpha-/-$ mice failed to induce disease (Fig. 3B), intramammary transfer of wildtype macrophages restored LPS-induced mammary inflammation identically to that observed in wild-type mice (Fig. 3C). Control C57BL/6 or $\mathrm{TNF} \alpha-/-$ glands infused with either wt or $\mathrm{TNF} \alpha-/-$ macrophages were normal. 

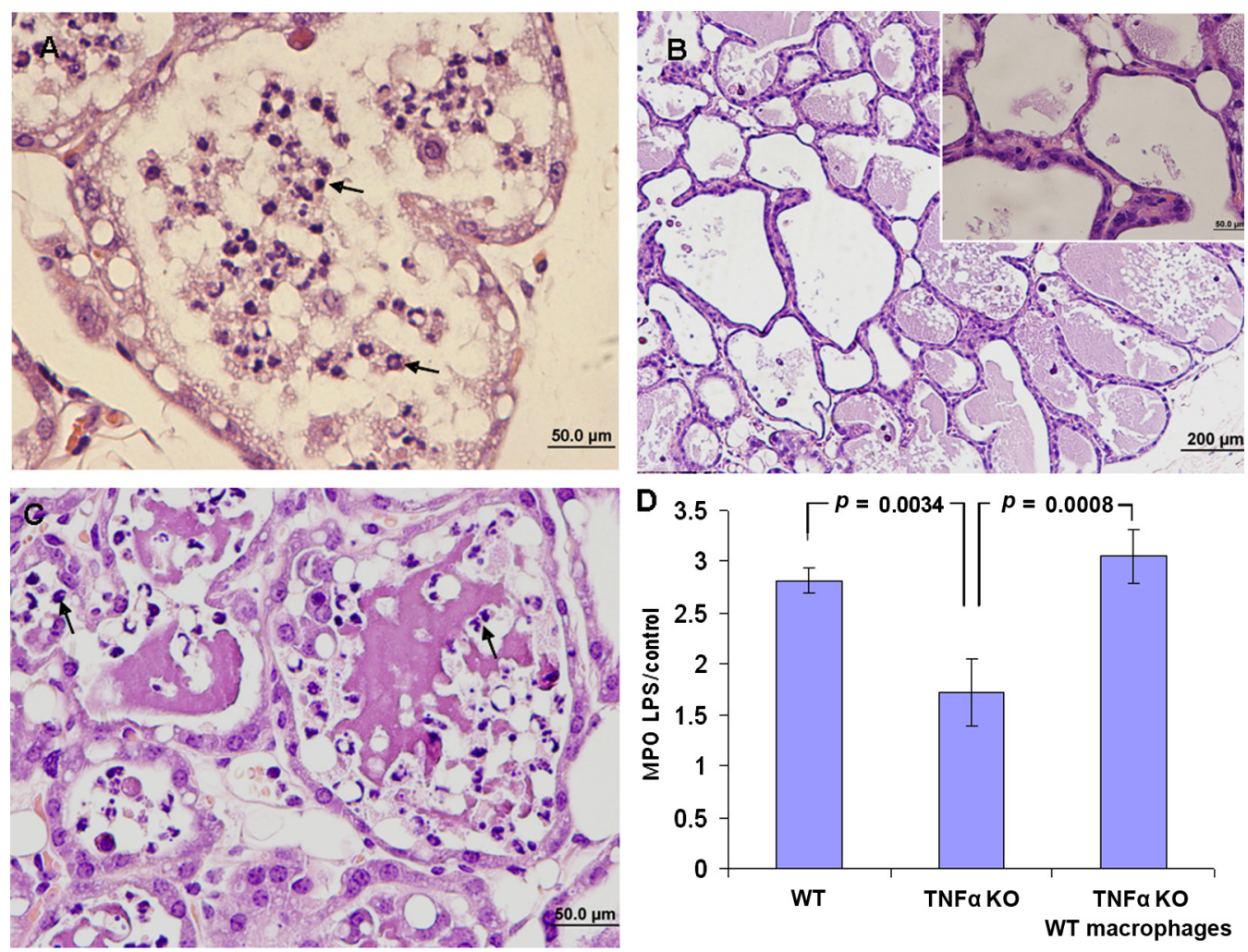

Figure 3. TNF $\alpha$ is an essential down-stream signal of LPS/TLR4 signaling on mammary alveolar macrophages mediating neutrophil recruitment. Mammary glands of lactating C57BL/6 and TNF $\alpha-/-$ mice were infused with $10 \mu \mathrm{g}$ LPS. H\&E staining of formalin-fixed mammary tissues $24 \mathrm{~h}$ after LPS inoculation $(\mathrm{A}-\mathrm{C})$. Massive recruitment of neutrophils into the alveolar space is seen in C57BL/6 mice (A and Fig. 6C) while no signs of inflammation are observed in TNFa $-/-$ mice (B and inset B). Intramammary transfer of C57BL/6 macrophages into TNF - /- mice restored LPS-induced mammary inflammation (Fig. 3C) identically to that in C57BL/6 mice. Neutrophil recruitment to the mammary gland was assessed by the MPO assay (D). A significant difference in relative (LPS to PBS-challenged gland) MPO activity was observed in mammary glands of $\mathrm{TNF} \alpha-/-$ mice after macrophage transfer compared with $\mathrm{C} 57 \mathrm{BL} / 6$ and TNF $\alpha-/-$ mice. Data are mean and S.E., $n \geq 6$ /group and $p$ values represent a comparison between groups using the Student $t$-test. Scale bars $50 \mu \mathrm{m}$ (A, C and inset B), $200 \mu \mathrm{m}$ (B). (A color version of this figure is available at www.vetres.org.)

Furthermore, the effect of the grafted macrophages was restricted to the infused gland, since LPS infusion of the contralateral gland had no effect. Taken together, these results indicate that TNF $\alpha$ is an essential down-stream signal of LPS/TLR4 signaling on mammary alveolar macrophages mediating neutrophil recruitment and inflammation.

\subsection{Neutrophil recruitment across the alveolar epithelium is IL1ß and IL8 dependent}

To study the role of IL1 $\beta$ and IL8 in the pathogenesis of LPS murine mastitis, IL1 receptor type 1 (IL1R -/-), IL8 receptor (IL8R -/-) gene-deficient mice and their respective wt C57BL/6 and BALB/c mice were 

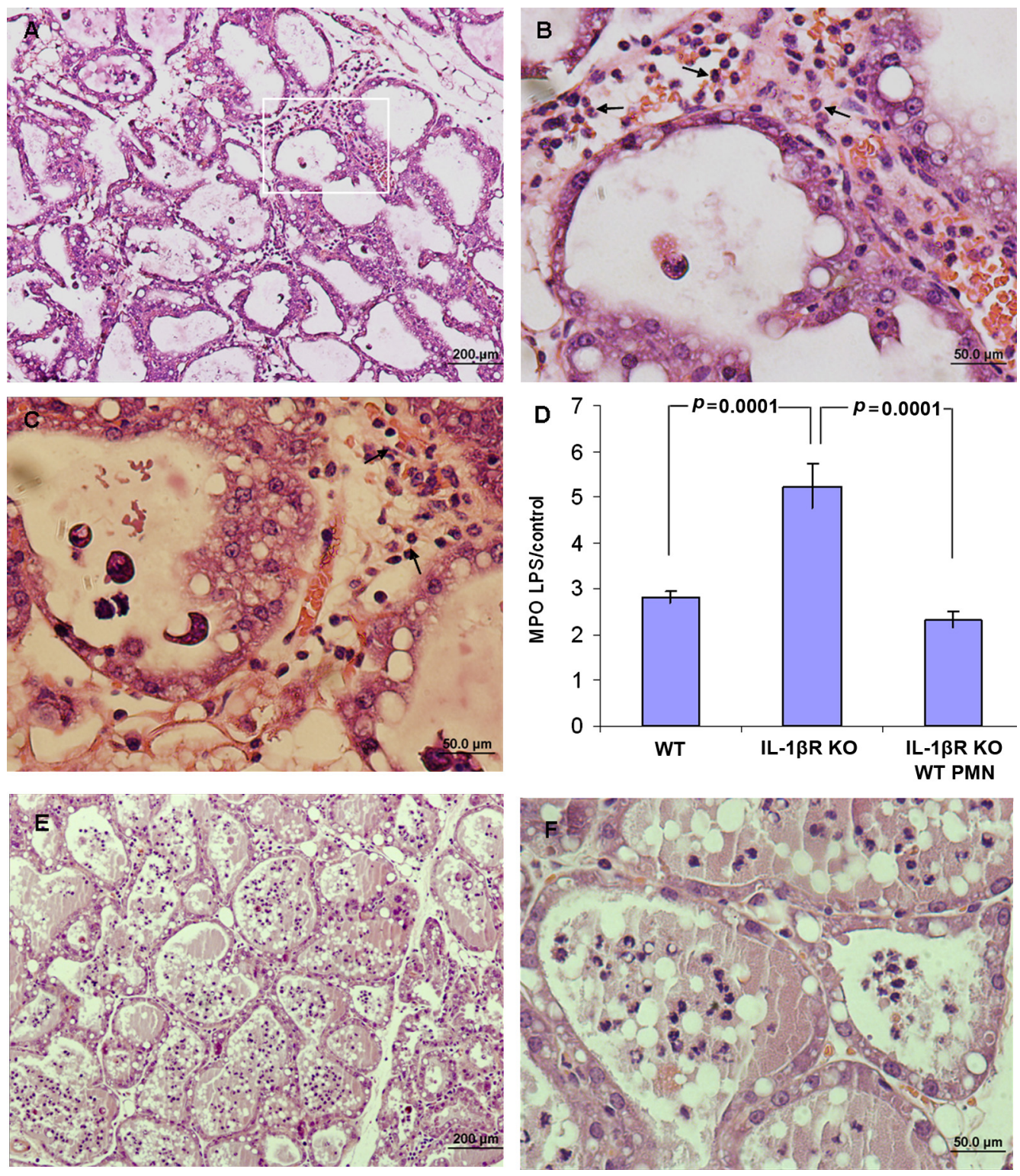

Figure 4. Neutrophil recruitment across the alveolar epithelium is IL1 $\beta$ dependent. Mammary glands of lactating IL1R $-/-$ mice were infused with $10 \mu \mathrm{g}$ LPS. H\&E staining of formalin-fixed mammary tissues $24 \mathrm{~h}$ after LPS inoculation $(\mathrm{A}-\mathrm{C})$. Recruited neutrophils (arrows) are trapped in congested capillaries and interstitium unable to transverse the mammary epithelium $(\mathrm{A}-\mathrm{C})$. This is better seen in B which is an enlargement of the inset area in A and also in C. Increased neutrophil recruitment to the mammary gland was indicated by the MPO assay (D). Significantly higher relative (LPS to PBS-challenged gland) MPO activity was observed in mammary glands of IL1R -/ - mice compared with $\mathrm{C} 57 \mathrm{BL} / 6$ mice. Adoptive transfer of $10^{6} \mathrm{wt}$ neutrophils restored normal neutrophil recruitment into the alveolar spaces (E and $\mathrm{F}$ ) which is also reflected by similar relative MPO activity (D). Data are mean and S.E., $n \geq 6 /$ group and $p$ values represent comparison between groups using the Student $t$-test. Scale bars $200 \mu \mathrm{m}$ (A), $50 \mu \mathrm{m}$ (B and C). (A color version of this figure is available at www.vetres.org.) 

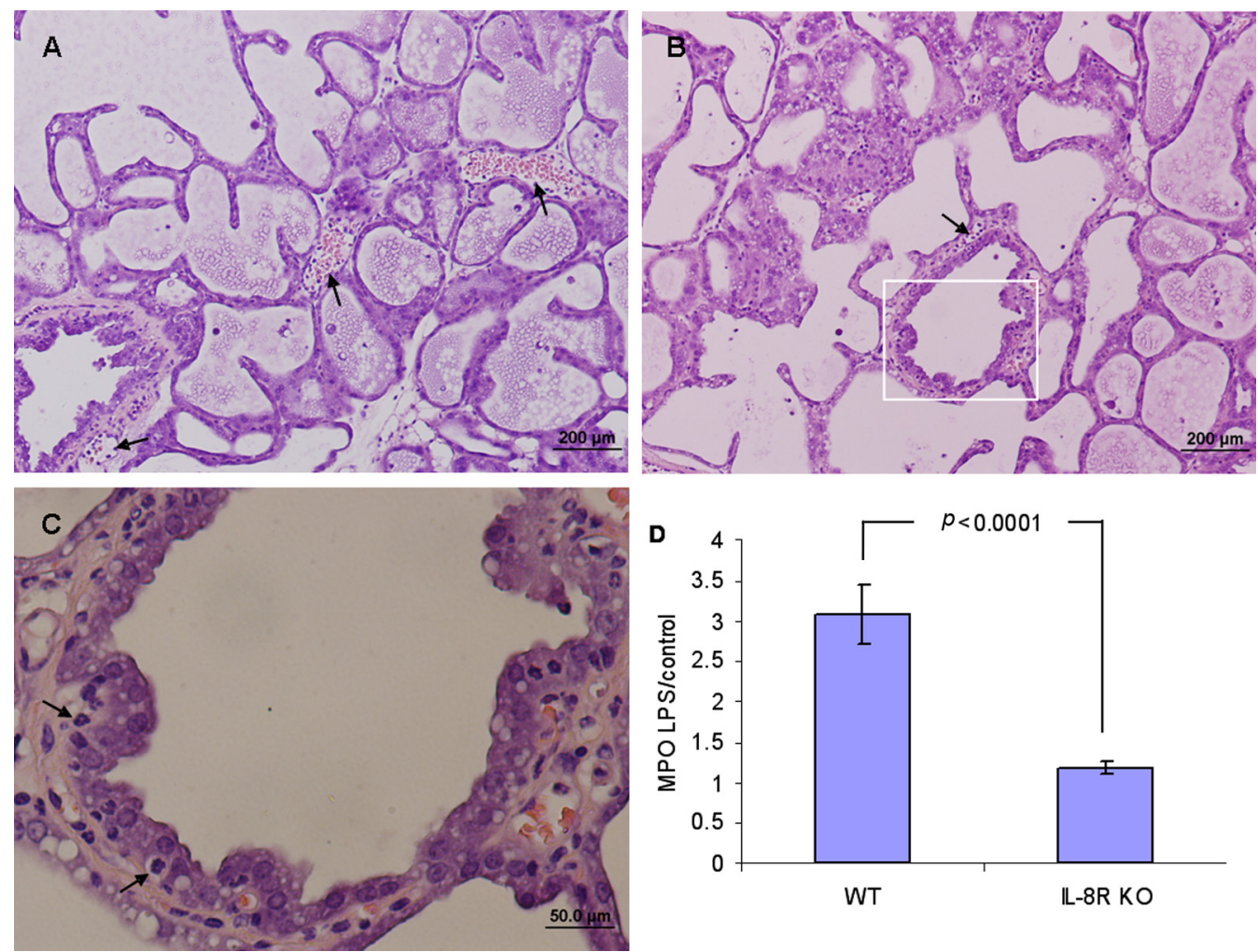

Figure 5. Neutrophil recruitment into the mammary gland and across the alveolar epithelium is IL18 dependent. Mammary glands of lactating IL18R $-/-($ CXCR2 $-/-)$ mice were infused with $10 \mu \mathrm{g}$ LPS. H\&E staining of formalin-fixed mammary tissues $24 \mathrm{~h}$ after LPS inoculation (A-C). Neutrophil recruitment into the mammary gland is markedly reduced (A and B). Recruited neutrophils are seen in capillaries and interstitium and trapped in between alveolar epithelial cells (arrows in $\mathrm{C}$ which is an inset of B) unable to transverse the epithelium to the milk space. Reduced neutrophil recruitment to the mammary gland was also indicated by the MPO assay (D). Significantly lower relative (LPS to PBS-challenged gland) MPO activity was observed in the mammary glands of IL18R $-/-$ mice compared with wt Balb/c mice. Data are mean and S.E., $n \geq 6$ /group and $p$ values represent a comparison between groups using the Student $t$-test. Scale bars $200 \mu \mathrm{m}$ (A and B), $50 \mu \mathrm{m}$ (C). (A color version of this figure is available at www.vetres.org.)

intramammarilly challenged with LPS. Histopathological examination of LPS-treated glands of IL1R $-/-$ mice revealed profound mastitis development characterized by massive recruitment of neutrophils into highly congested blood vessels and interstitium (Figs. 4A-4C). In the absence of the IL1R signal, neutrophil influx into the mammary gland was increased as reflected by higher levels of MPO activity in mammary gland homogenates (Fig. 4D). However, while in wt mice, as previously described, massive neutrophil recruitment into the alveolar and duct spaces was observed, in IL1R -/mice only few neutrophils were observed in these spaces. Instead, neutrophils accumulated in highly congested blood vessels and in the interstitial space (Figs. 4B and 4C). These observations suggest that neutrophil recruitment 
across the mammary epithelial barrier in response to LPS/TLR4 signaling on alveolar macrophages is dependent on IL1R signaling.

Adoptive transfer of wt neutrophils into IL1R -/- mice before intramammary LPS challenge was sufficient to restore normal neutrophil recruitment into the alveolar spaces as demonstrated in Figures 4E and 4F and reflected by similar levels of MPO activity $(p<0.1)$ (Fig. 4D). Interestingly, neutrophil accumulation in blood vessels and the interstitium was not observed after adoptive transfer of wt neutrophils.

Histopathological examination of LPS-treated glands of IL8R $-/-(\mathrm{CXCR} 2-/-)$ mice revealed a different situation in comparison to that described above. Although some neutrophil recruitment to the blood vessels and interstitium was observed in the absence of the IL8 (KC and MIP-2 in the mouse) signal (Figs. 5A and 5B), neutrophil influx into the mammary gland was decreased as reflected by lower levels of MPO activity in mammary gland homogenates $(p<0.0001)$ (Fig. 5D). Recruited neutrophils are seen trapped on the basolateral side of the alveolar epithelium unable to transverse into the alveolar space (Fig. 5C).

\section{5. iNOS-derived NO is regulating neutrophil recruitment into the mammary gland}

To investigate the role of iNOS-derived NO as a down-stream signal elicited by LPS/TLR4 signaling, iNOS $-/-$ mice were intramammarilly challenged with LPS. Histopathological examination of LPS-treated glands revealed profound mastitis development characterized by massive recruitment of neutrophils into the alveolar spaces and milk ducts. No signs of inflammation were present in the interstitial tissue, and the blood vessels as well as the ductal and alveolar epithelium maintained normal morphology (Figs. 6A and 6B). Signs of disease and neutrophil recruitment were no different in wt (C57BL/6) (Figs. 3A and 6C) versus the iNOS knockout mouse although more neutrophils were observed in the milk spaces of the knockout mice. This difference is further substantiated by the observation that MPO activity in the LPS infused gland of iNOS knockout mice was significantly higher than the MPO activity in LPS infused glands of wt mice $(p=0.0159)$ (Fig. 6D).

\section{DISCUSSION}

Our studies using adoptive transfer of normal macrophages into the mammary gland of TLR4-deficient $\mathrm{C} 3 \mathrm{H} / \mathrm{HeJ}$ mice challenged with LPS showed that alveolar macrophages are sufficient to elicit neutrophil recruitment into the alveolar space [10]. Here we show that TLR4normal $\mathrm{C} 3 \mathrm{H} / \mathrm{HeN}$ mice depleted of alveolar macrophages were completely refractory to LPS intramammary challenge. Taken together, these results indicate that alveolar macrophages are both sufficient and essential for neutrophil recruitment elicited by LPS/TLR4 signaling in the mammary gland. Interestingly, similar results were reported in a murine model of inhaled LPS-induced lung inflammation where LPS/TLR4 signaling on pulmonary alveolar macrophages was both sufficient and essential for neutrophil recruitment into the alveolar spaces [14]. As recently suggested, LPS/TLR4 signaling on bone marrow-derived immune cells might be essential for neutrophil recruitment in barrier epithelial sites such as lung alveoli, intestinal tract, skin, eyes, mouth and reproductive organs [1].

The down-stream mediators of this LPS/ TLR4 signaling is still unknown and prime candidates are the pro-inflammatory cytokines TNF $\alpha$ and IL1 $\beta$, the chemokine IL8 (MIP-2 and $\mathrm{KC}$ in mice) and the inflammatory mediator NO. Increased gene expression and production of these factors by mammary cells, most probably mediated by the transcription factor NFKB $[20,21]$, have been demonstrated both in vitro and in vivo in E. coli and LPS bovine mastitis $[15,31,34,36,43]$. We show here that LPS/ TLR4 signaling by alveolar macrophages followed by elevated mammary concentrations of TNF $\alpha$, IL1 $\beta$, MIP-2 and KC are important mediators of inflammation induced by bacteria and bacterial products. Hence for, we investigated the role of TNF $\alpha$, IL1 $\beta$, IL8 and NO as mediators and down-stream signal of neutrophil recruitment elicited by LPS/TLR4 signaling on alveolar macrophages. 

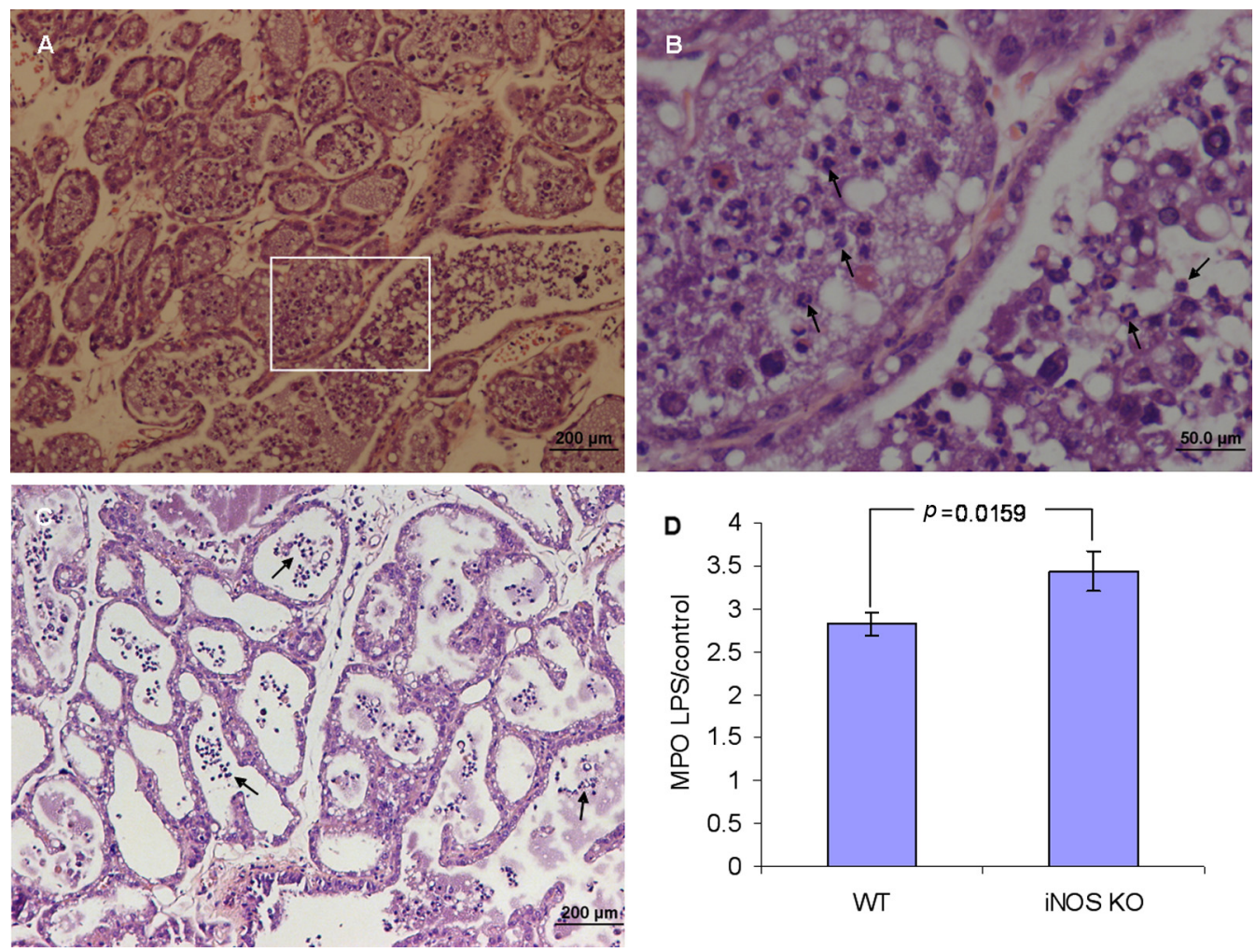

Figure 6. Neutrophil recruitment into milk spaces $24 \mathrm{~h}$ after intramammary infusion of $10 \mu \mathrm{g}$ LPS in iNOS $-/-$ (A and inset of A inB) and wt C57BL/6 mice (C). H\&E staining of formalin-fixed mammary tissues $(\mathrm{A}-\mathrm{C})$. Neutrophil recruitment to the mammary gland was assessed by the MPO assay (D). Significant difference in relative (LPS to PBS-challenged gland) MPO activity was observed in the mammary glands of iNOS $-/-$ mice compared with C57BL/6 mice. Data are mean and S.E., $n \geq 6$ /group and $p$ values represent comparison between groups using the Student $t$-test. Scale bars $200 \mu \mathrm{m}$ (A and C), $50 \mu \mathrm{m}$ (B). (A color version of this figure is available at www.vetres.org.)

We show here that TNF $\alpha$ produced by mammary alveolar macrophages in response to LPS/ TLR4 signaling is an essential mediator eliciting blood neutrophil recruitment into the milk spaces. Intramammary infusion of TNF $\alpha$ was reported to induce neutrophil recruitment into the milk in lactating cows and sheep [26, 42], but failed to reproduce the full clinical disease. The high levels of blood and milk TNF $\alpha$ frequently reported to peak $12-24 \mathrm{~h}$ after challenge in LPS and E. coli mastitis are probably late events produced by recruited leukocytes $[17,21,43]$ and other tissues [38]. The low levels of $\mathrm{TNF} \alpha$, locally produced by mammary alveolar macrophages, are probably undetected in milk and blood and exert local autocrine and paracrine proinflammatory effects, which are amplified, synchronized and propagated by effectors produced by other mammary cells. Activation of polar bovine mammary epithelial cells by TNF $\alpha$ was reported to elicit production and release of high levels of IL8 [8]. Current models of the neutrophil transepithelial migration postulate that induced secretion of CXC chemokines from the basolateral surface of epithelial cells initiates neutrophil influx by signaling through chemokine receptors on neutrophils. Mice have a single receptor for $\mathrm{CXC}$ 
chemokines homologous to the human and bovine CXCR1 and CXCR2. This receptor (CXCR2) is activated by KC and MIP-2, the functional homologs of human and bovine CXCL8 (IL8) [16]. Several previous studies implicated the importance of IL8 in neutrophil recruitment during mastitis. Our results suggest that IL8 signaling is essential for recruitment of blood neutrophils across the mammary alveolar epithelium into the milk spaces. In the absence of IL8 signaling, the number of neutrophils recruited into the mammary gland was reduced and those recruited were unable to cross the epithelial barrier. Similar results were reported with uropathogenic $E$. coli (UPEC) infection model in IL8R -/- mice where neutrophil entrapment under the urinary mucosal epithelium was observed [12, 13]. Furthermore, both urinary infection and inhaled LPS-induced lung inflammation studies demonstrated that neutrophil recruitment required functional IL8R on both epithelial cells and neutrophils [9, 29, 35]. These studies and our results might indicate that expression of IL8R on the mammary epithelial cells is required for neutrophil migration across this barrier. Interestingly, specific CXCR2 gene polymorphism was associated with in vitro neutrophil functions and susceptibility to mastitis in dairy cows $[28,44]$.

IL1 $\beta$ is another potent proinflammatory cytokine implicated to play a role in many inflammatory conditions and high levels were measured in the mammary tissues and milk of mastitic animals. Although recombinant IL1 $\beta$ was reported to cause neutrophil recruitment in various organs, intramammary infusion of IL1 $\beta$ and IL1 receptor antagonist in LPSinduced bovine mastitis suggested that IL1 $\beta$ does not mediate its effects in the milk compartments [33, 41]. Furthermore, apical activation of bovine [18] or murine (our unpublished results with EPH4 cells) polar mammary epithelial cells by LPS or $E$. coli failed to induce IL1 $\beta$ production by these cells and other mediators like $\mathrm{TNF} \alpha$ might be the primary activator of mammary epithelium and endothelial cells. We have been able to show here that IL $1 \beta$ signaling is essential for recruitment of blood neutrophils across the mammary alveolar epithelium. Intramammary challenge with LPS in
IL1R - / - mice resulted in massive recruitment of neutrophils into the mammary gland as indicated by the MPO activity and histopathology. However, recruited neutrophils were unable to cross the alveolar epithelial cells and were trapped in the circulation and interstitial spaces. Adoptive transfer of wt neutrophils into IL1R - - mice just before intramammary LPS challenge was sufficient to restore normal recruitment of blood neutrophils into the mammary alveolar space. The large number of recruited neutrophils observed after this adoptive transfer is unlikely to be constituted only of the adoptively transferred wt neutrophils. Trans-signaling by wt neutrophils might have facilitated normal recruitment of IL1R -/- neutrophils which were not observed trapped in the circulation or interstitium. A possible mechanism might be the formation of "neutrophil permissive sites" by IL1 $\beta$ activated neutrophils which open migration routes for the IL1 $\beta \mathrm{R}-/-$ neutrophils [39], however, further studies are required to elucidate the mechanism of this phenomenon in the mammary gland. These results indicate that IL1 $\beta$ signaling on blood neutrophils is both sufficient and essential to elicit normal neutrophil recruitment in response to intramammary LPS challenge.

Previous studies showed increased iNOS expression and NO production by mammary alveolar epithelium in response to LPS $[23,31]$ and elevated levels of milk NO in experimental LPS and E. coli bovine mastitis [4]. However, intramammary infusion of the iNOS inhibitor did not affect the course of the disease $[5,6]$. We report here that neutrophil recruitment into the mammary gland in response to LPS was increased in iNOSdeficient mice. This observation is in line with previous studies showing that down-regulation of CXCR2 on neutrophils [30] and reduced neutrophil migration in sepsis are both mediated by iNOS-derived NO [7, 19]. Taken together, our results might indicate that iNOS-derived $\mathrm{NO}$ is an important regulator of inflammation in the mammary gland.

In conclusion we would like to suggest the following model describing the inflammation cascade initiated by bacterial LPS in the mammary alveolar space. Based on this and our 
previous study [10] we suggest that the strong proinflammatory effect of bacterial LPS in the mammary gland is mediated by TLR4 on alveolar macrophages eliciting the production of $\mathrm{TNF} \alpha$. The small number of alveolar macrophages which is also maintained during the mammary inflammation is unlikely to be the source of the high levels of cytokines and chemokines measured in the mammary gland by us and others $[21,40]$. We predict that the macrophage derived TNF $\alpha$ exert local paracrine effects on the mammary epithelium which is amplified and propagated by these cells resulting in the production of high levels of effectors such as IL1 $\beta$, IL8 and NO. In agreement with this hypothesis we showed that IL1 $\beta$ and IL8 signaling are essential for neutrophil recruitment which is regulated by NO.

Acknowledgements. This work was supported by the Israel Science Foundation grant No. 193/08.

\section{REFERENCES}

[1] Andonegui G., Mice that exclusively express TLR4 on endothelial cells can efficiently clear a lethal systemic Gram-negative bacterial infection, J. Clin. Invest. (2009) 119:1921.

[2] Bannerman D.D., Paape M.J., Hare W.R., Sohn E.J., Increased levels of LPS-binding protein in bovine blood and milk following bacterial lipopolysaccharide challenge, J. Dairy Sci. (2003) 86:3128-3137.

[3] Bar D., Tauer L.W., Bennett G., Gonzalez R.N., Hertl J.A., Schukken Y.H., et al., The cost of generic clinical mastitis in dairy cows as estimated by using dynamic programming, J. Dairy Sci. (2008) 91:2205-2214.

[4] Blum J.W., Dosogne H., Hoeben D., Vangroenweghe F., Hammon H.M., Bruckmaier R.M., Burvenich C., Tumor necrosis factor-alpha and nitrite/nitrate responses during acute mastitis induced by Escherichia coli infection and endotoxin in dairy cows, Domest. Anim. Endocrinol. (2000) 19:223-235.

[5] Bouchard L., Blais S., Desrosiers C., Zhao X., Lacasse P., Nitric oxide production during endotoxininduced mastitis in the cow, J. Dairy Sci. (1999) 82:25742581 .

[6] Boulanger V., Zhao X., Lauzon K., Lacasse P., Effects of nitric oxide on bovine polymorphonuclear functions, Can. J. Vet. Res. (2007) 71:52-58.

[7] Doerschuk C.M., NO and neutrophils during sepsis: NO says "Yes" to sequestration but "No" to migration, Am. J. Respir. Crit. Care Med. (2004) 170:205-206.
[8] Fitzgerald D.C., Meade K.G., McEvoy A.N., Lillis L., Murphy E.P., MacHugh D.E., Baird A.W., Tumour necrosis factor-[alpha] (TNF-[alpha]) increases nuclear factor [kappa]B (NF[kappa]B) activity in and interleukin8 (IL-8) release from bovine mammary epithelial cells, Vet. Immunol. Immunopathol. (2007) 116:59-68.

[9] Godaly G., Hang L., Frendeus B., Svanborg C., Transepithelial neutrophil migration is CXCR1 dependent in vitro and is defective in IL-8 receptor knockout mice, J. Immunol. (2000) 165:5287-5294.

[10] Gonen E., Vallon-Eberhard A., Elazar S., Harmelin A., Brenner O., Rosenshine I., et al., Toll-like receptor 4 is needed to restrict the invasion of Escherichia coli $\mathrm{P} 4$ into mammary gland epithelial cells in a murine model of acute mastitis, Cell. Microbiol. (2007) 9:2826-2838.

[11] Halasa T., Huijps K., Osteras O., Hogeveen H., Economic effects of bovine mastitis and mastitis management: a review, Vet. Q. (2007) 29:18-31.

[12] Hang L., Haraoka M., Agace W.W., Leffler H., Burdick M., Strieter R., Svanborg C., Macrophage inflammatory protein-2 is required for neutrophil passage across the epithelial barrier of the infected urinary tract, J. Immunol. (1999) 162:3037-3044.

[13] Hang L., Frendéus B., Godaly G., Svanborg C., Interleukin 8 receptor knockout mice have subepithelial neutrophil entrapment and renal scarring following acute pyelonephritis, J. Infect. Dis. (2000) 182:1738-1748.

[14] Hollingsworth J.W., Chen B.J., Brass D.M., Berman K., Gunn M.D., Cook D.N., Schwartz D.A., The critical role of hematopoietic cells in lipopolysaccharide-induced airway inflammation, Am. J. Respir. Crit. Care Med. (2005) 171:806-813.

[15] Lahouassa H., Moussay E., Rainard P., Riollet C., Differential cytokine and chemokine responses of bovine mammary epithelial cells to Staphylococcus aureus and Escherichia coli, Cytokine (2007) 38:12-21.

[16] Lahouassa H., Rainard P., Caraty A., Riollet C., Identification and characterization of a new interleukin-8 receptor in bovine species, Mol. Immunol. (2008) 45:1153-1164.

[17] Lee J.W., Bannerman D.D., Paape M.J., Huang M.K., Zhao X., Characterization of cytokine expression in milk somatic cells during intramammary infections with Escherichia coli or Staphylococcus aureus by real-time PCR, Vet. Res. (2006) 37:219-229.

[18] McClenahan D.J., Sotos J.P., Czuprynski C.J., Cytokine response of bovine mammary gland epithelial cells to Escherichia coli, coliform culture filtrate, or lipopolysaccharide, Am. J. Vet. Res. (2005) 66:15901597.

[19] Napimoga M.H., Vieira S.M., Dal-Secco D., Freitas A., Souto F.O., Mestriner F.L., et al., Peroxisome proliferator-activated receptor-\{gamma $\}$ ligand, 15deoxy-\{Delta $\} 12,14$-prostaglandin $\mathrm{J} 2$, reduces neutrophil migration via a nitric oxide pathway, J. Immunol. (2008) 180:609-617. 
[20] Notebaert S., Carlsen H., Janssen D., Vandenabeele P., Blomhoff R., Meyer E., In vivo imaging of NF-kappaB activity during Escherichia coli-induced mammary gland infection, Cell. Microbiol. (2008) 10:1249-1258.

[21] Notebaert S., Demon D., Vanden Berghe T., Vandenabeele P., Meyer E., Inflammatory mediators in Escherichia coli-induced mastitis in mice, Comp. Immunol. Microbiol. Infect. Dis. (2008) 31:551-565.

[22] Olde Riekerink R.G., Barkema H.W., Kelton D.F., Scholl D.T., Incidence rate of clinical mastitis on Canadian dairy farms, J. Dairy Sci. (2008) 91:1366-1377.

[23] Onoda M., Inano H., Localization of nitric oxide synthases and nitric oxide production in the rat mammary gland, J. Histochem. Cytochem. (1998) 46:1269-1278.

[24] Paape M.J., Bannerman D.D., Zhao X., Lee J.W., The bovine neutrophil: structure and function in blood and milk, Vet. Res. (2003) 34:597-627.

[25] Paape M., Mehrzad J., Zhao X., Detilleux J., Burvenich C., Defense of the bovine mammary gland by polymorphonuclear neutrophil leukocytes, J. Mammary Gland Biol. Neoplasia (2002) 7:109-121.

[26] Persson K., Colditz I.G., Flapper P., Franklin N.A., Seow H.F., Cytokine-induced inflammation in the ovine teat and udder, Vet. Immunol. Immunopathol. (1996) 53: 73-85.

[27] Rainard P., Riollet C., Innate immunity of the bovine mammary gland, Vet. Res. (2006) 37:369-400.

[28] Rambeaud M., Clift R., Pighetti G.M., Association of a bovine CXCR2 gene polymorphism with neutrophil survival and killing ability, Vet. Immunol. Immunopathol. (2006) 111:231-238.

[29] Reutershan J., Morris M.A., Burcin T.L., Smith D.F., Chang D., Saprito M.S., Ley K., Critical role of endothelial CXCR2 in LPS-induced neutrophil migration into the lung, J. Clin. Invest. (2006) 116:695-702.

[30] Rios-Santos F., Alves-Filho J.C., Souto F.O., Spiller F., Freitas A., Lotufo C.M., et al., Down-regulation of CXCR2 on neutrophils in severe sepsis is mediated by inducible nitric oxide synthase-derived nitric oxide, Am. J. Respir. Crit. Care Med. (2007) 175:490-497.

[31] Schmitz S., Pfaffl M.W., Meyer H.H., Bruckmaier R.M., Short-term changes of mRNA expression of various inflammatory factors and milk proteins in mammary tissue during LPS-induced mastitis, Domest. Anim. Endocrinol. (2004) 26:111-126.

[32] Shpigel N.Y., Winkler M., Ziv G., Saran A., Clinical, bacteriological and epidemiological aspects of clinical mastitis in Israeli dairy herds, Prev. Vet. Med. (1998) 35:1-9.

[33] Shuster D.E., Kehrli M.E. Jr., Administration of recombinant human interleukin 1 receptor antagonist during endotoxin-induced mastitis in cows, Am. J. Vet. Res. (1995) 56:313-320.
[34] Shuster D.E., Lee E.K., Kehrli M.E. Jr., Bacterial growth, inflammatory cytokine production, and neutrophil recruitment during coliform mastitis in cows within ten days after calving, compared with cows at midlactation, Am. J. Vet. Res. (1996) 57:1569-1575.

[35] Svensson M., Irjala H., Svanborg C., Godaly G., Effects of epithelial and neutrophil CXCR2 on innate immunity and resistance to kidney infection, Kidney Int. (2008) 74:81-90

[36] Swanson K.M., Stelwagen K., Dobson J., Henderson H.V., Davis S.R., Farr V.C., Singh K. Transcriptome profiling of Streptococcus uberis-induced mastitis reveals fundamental differences between immune gene expression in the mammary gland and in a primary cell culture model, J. Dairy Sci. (2009) 92:117-129.

[37] Van Rooijen N., Sanders A., Liposome mediated depletion of macrophages: mechanism of action, preparation of liposomes and applications, J. Immunol. Methods (1994) 174:83-93.

[38] Vels L., Rontved C.M., Bjerring M., Ingvartsen K.L., Cytokine and acute phase protein gene expression in repeated liver biopsies of dairy cows with a lipopolysaccharide-induced mastitis, J. Dairy Sci. (2009) 92:922-934.

[39] Voisin M.-B., Woodfin A., Nourshargh S., Monocytes and neutrophils exhibit both distinct and common mechanisms in penetrating the vascular basement membrane in vivo, Arterioscler. Thromb. Vasc. Biol. (2009) 29:1193-1199.

[40] Wall R., Powell A., Sohn E., Foster-Frey J., Bannerman D., Paape M., Enhanced host immune recognition of mastitis causing Escherichia coli in CD-14 transgenic mice, Anim. Biotechnol. (2009) 20:1-14.

[41] Waller K.P., Modulation of endotoxin-induced inflammation in the bovine teat using antagonists/inhibitors to leukotrienes, platelet activating factor and interleukin 1 beta, Vet. Immunol. Immunopathol. (1997) 57:239-251.

[42] Watanabe A., Yagi Y., Shiono H., Yokomizo Y., Effect of intramammary infusion of tumour necrosis factor-alpha on milk protein composition and induction of acute-phase protein in the lactating cow, J. Vet. Med. B Infect. Dis. Vet. Public Health (2000) 47:653-662.

[43] Yang W., Zerbe H., Petzl W., Brunner R.M., Gunther J., Draing C., et al., Bovine TLR2 and TLR4 properly transduce signals from Staphylococcus aureus and $E$. coli, but $S$. aureus fails to both activate NF-kappaB in mammary epithelial cells and to quickly induce TNFalpha and interleukin-8 (CXCL8) expression in the udder, Mol. Immunol. (2008) 45:1385-1397.

[44] Youngerman S.M., Saxton A.M., Oliver S.P., Pighetti G.M., Association of CXCR2 polymorphisms with subclinical and clinical mastitis in dairy cattle, J. Dairy Sci. (2004) 87:2442-2448. 